\title{
Determinants of Net Sale Average (NSA) of Orthodox Black Tea Factories in High Elevation, Sri Lanka
}

\author{
D. D. R. M. Karunaratne ${ }^{1}$, R. A. P. I. S. Dharmadasa ${ }^{1}$, R. M. S. D. Rathnayaka ${ }^{1}$, \\ E. A. J. K. Edirisinghe ${ }^{2}$ \\ ${ }^{1}$ Uva Wellassa University, Badulla, Sri Lanka \\ ${ }^{2}$ Sri Lanka Tea Board, Colombo, Sri Lanka
}

\begin{abstract}
Secondary data proved that high grown teas are losing their position as the highest Elevation Average (EA) recorded over the years. As EA is determined by the factory Net Sale Average (NSA), factors affecting NSA are responsible for fluctuations of EA. This study attempts to identify those factors which affect NSA of orthodox black tea factories in high elevation. Data were collected for tea factories representing agro climatic regions in high elevation. Fixed effect panel data regression analysis was employed for the econometric analysis. Results revealed that NSA is determined by main grade percentage, own leaf quantity, best leaf standard, quality certification of factories and number of brokers involved in the selling process. However, Udu Pussellawa sub region shows negative relationship for own leaf and best leaf standard whereas Uva sub region shows negative relationship only for the main grade percentage. The overall results indicate that high elevation factory NSA is determined by the quality of the raw material and final output.
\end{abstract}

Key words: High Elevation, Tea, Determinants, NSA, EA, Quality, Panel data

\section{Introduction}

The prices of agricultural commodities have been carrying high significant not only economically but also politically (Farid and Rahman, 2002). These prices strongly influence the level of farm income as well as the welfare of consumers. On the other hand, in a situation where there are various influences with economic restrictions from western countries for export industries all over the world and exporting industries are facing many problems, plantation crop industry were able to withstand and make the country more survive and more prosperous as a result of the agricultural nature of the industry. It is a fact that farmers, marketing and supply firms and government officials have to make many decisions 
that require knowledge of price fluctuations (Farid and Rahman, 2002). Therefore identifying existing problems in both within the country and in the international market will be rather effective for the industry.

For tea, high prices gained in the auction provide some proportion of profits to the leaf suppliers called reasonable price payable for bought leaf. If substantial high level of prices could be maintained throughout the year, it would motivate the growers to place the greater emphasis on good agricultural practices. Meanwhile fertilizer subsidy program and higher prices encourage the smallholders who contributed over 74 present of the island wide production (Tea Traders Association, 2011).

Black orthodox tea is the type by which Ceylon is recognized in global market; its particular characteristic is that the leaves are fully fermented in the manufacturing process. The quality always interconnected with the diversity of the flavor of Ceylon Tea (Mohammed and Dahanayake, 2008). This quality is created by the variability of the climate in tea growing areas. Ceylon tea is grown and produced in seven major agro-climatic regions; namely Uva, Nuwara Eliya, Udu Pussellawa, Kandy, Dimbula and Ruhuna. Each of these regions gives its own flavor to the tea produced in their region. The seven major agro-climatic regions are further divided into 38 sub-regions, each with its own distinctive characteristics. Because of the country's small land area, the central mountain range has a considerable influence on the climate. As a result of climatic variations, different flavors of tea have been created in different regions that are unique for them (Fernando, 2008). For an instance, Uva flavor cannot be reproduced anywhere else, and is the most sought- after in world. Teas from Uva region have been getting high price in the public auction without considering any other factors affecting to the price. Similarly, western side produces high quality teas with their special flavor whose special quality develops as a result of dry conditions and very cold nights.

When considering the contribution to the national economy, tea industry in Sri Lanka is the second-highest exports earner after apparels which are having $17.6 \%$ of total exports in Sri Lanka (Central Bank of Sri Lanka, 2011). From the beginning of tea production, it has accounted for more than two-thirds of the country's agricultural export earnings, contributing about 4 per cent to the GDP (Central Bank of Sri Lanka, 2011). According to the statistics of the Sri Lanka Tea Board, tea production in year 2010 was 331.4 million $\mathrm{kg}$ and the average auction price of the Colombo tea auction was US \$ 3.28 per kilogram. High grown tea was 
responsible for quality teas among those millions of kilograms of teas which have been earned money for the Sri Lankan economy over years (Sri Lanka Tea Board, 2010).

Tea price is determined by public auction and then producers receive high prices according to the current demand at the market. This situation clearly reflects that producer has to satisfy with the prices settled in auction, as they do not actively participate in the selling process. Then intermediaries come into force to represent the producer and local and international buyers at the sale. Based on the total proceeds from the sales and its quantity, producer accounts their monthly income for one kilogram. Each tea factory is having that value named Net Sale Average (NSA) and they make further improvements based on the NSA. Besides NSA of the factory, Elevation Average (EA), the unit price prepared for the relevant region is also an important value to figure out the income of the factory and their individual performance compared with the region.

NSA is the price of one kilogram of tea produced by a particular factory. It is calculated from the total proceeds gained by the factory for a month and dividing to the total quantity sold within that particular month. This price is useful in determining the profit margin of the factory. Therefore, it could be noted that analyzing factors affecting NSA would help to have better understanding about the demand of the teas produced and the improvements that should be considered to be made.

Green leaves provided from estate belongs to the factory are called own leaves and leaves supplied from the outside estates and small holders are called other estate leaves and bought leaves respectively. If the factory NSA is able to exceed their EA for the particular elevation more than 20 percent buyers (bought leaf factories) have to pay reasonable price or the incentive to the bought leaf suppliers (Sri Lanka Tea Board, 2010).

Green leaf is a starting point for tea processing. It is, therefore, vital to pluck $2-3$ tender leaves that are free of physical damage in order to produce quality tea. Tender leaf is usually defined as good leaf or the standard shoot because it contains $20 \%$ more polyphenols than mature leaf. The amount of polyphenols decreases as the leaves mature (Polyphenols undergo oxidation when plucked leaf is processed) (Zoysa, 2008). And the final quality of made tea depends on compounds resulting from oxidation.

In up country where quality is the main consideration, it is desirable to pluck the definitive two leaves and a bud (Mohammad and Dahanayaka, 2008). However, in practice, a fair 
amount of mature leaf is bought to the factory. The possible reason for that is the cost of plucking, which is the highest component in the overall cost of production. In rush crop period when plant growth rate is high and when there are not sufficient workers to pluck them all, plantation management is going to coarse plucking as a solution.

According to the secondary data, there is an increase in the tea prices in three main regions (High, Mid and Low). However, in comparison to prices of high grown and medium grown teas, low grown teas have gained higher prices from 1990 to 2010 (see fig 1). Thus, as the EA is formulated by NSA of the tea factories, the NSA is responsible for any fluctuations that occur in EA. In that scenario, studying the determinants of NSA becomes the basement for the major problem of price declining in high elevation in comparison to prices of other two categories.

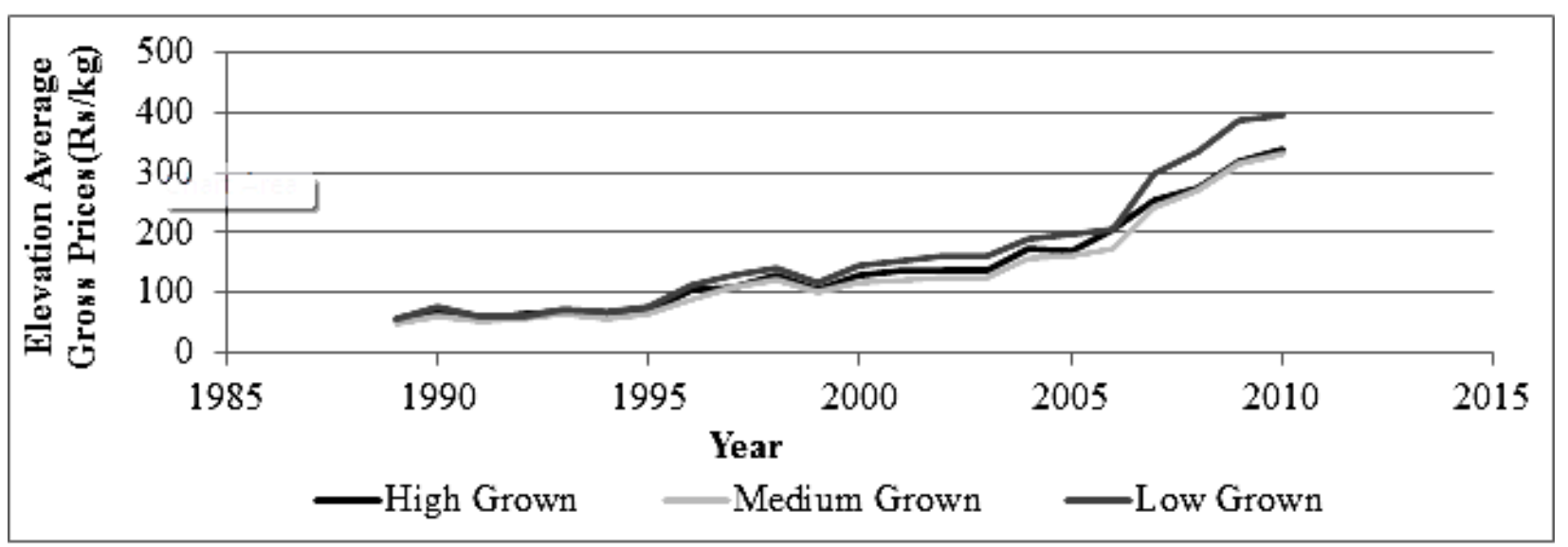

Source: Sri Lanka Tea Board

Fig 1: Elevation Average (EA) of Gross Price at Colombo Auction

Analyzing the determinants of NSA in high elevation can be considered as an individual analysis for one region. And that will be more important when analyzing the factors comparing with other two elevations. Searching the root cause for price decline in high elevation will be facilitated further improvements to build up previous market share for high grown tea. Considering above mentioned facts and since the current supply of high grown tea does not meet the market requirements of the global market, this study would be great importance for uplift the tea industry especially on high grown teas.

Basically, NSA of a particular factory represents the revenue which is gained from both main grades and off grades. Therefore, they have to maintain proper percentages among main grades 
and off grades in order to achieve high NSA. In fact, there can be more factors that affect the NSA to fluctuate in a particular factory. Therefore, without having clear idea about these factors and influence of them for the NSA, it would be rather critical for the factory in near future.

This study could be useful for the development programs that are aiming to increase the price of the made tea. Producer will be benefited when they have perfect market intelligent on driving forces for different prices of tea, the relationship between prices received for a lot and its grade and the origin of the company or region, which eventually influences on tea prices. The results may influence managers to alter production, harvesting, and/or processing procedures so they can increase profit from tea. If premiums and discounts are associated with company management, management practices can be evaluated for adoption or dropping out of depending on the relative costs and benefits (Anon, 2005). Hence, managers can adjust harvesting and processing practices to respond to price signals. Price differentials may provide incentives to alter varieties produced, harvesting methods, or processing techniques. It is the most important outcome of analyzing the factors affecting for tea prices.

In econometric analysis, the real benefits of panel data appeared in most fragile. It discussed that the panel data is offered the unique ability to deal with the contamination of econometric relationships by unobservable fixed effects. And panel estimators are superior when the presence of measurement error and estimates is unclear but have to compromise the quality of them. Pooled cross and time-series data for the analysis of growth equations is that the region or country-specific effects can be controlled for, e.g. by using a dynamic fixed-effect estimator (DFE) (Bassanini and Scarpetta, 2001). It could be replaced with this study also with tea factories as cross sectionals and monthly repeated data as time series data. In that scenario panel estimation is most appropriate technique, to minimize the errors in data when both time and cross sectional effect in essential for reach the objective.

\section{Methodology}

Research is carried out to the high elevation lands above $1200 \mathrm{~m}$ and sample is represented every sub district in high elevation. Total numbers of registered tea factories are 158, they are currently in operation, and located in high elevation. They were selected as the population of this research and simple random sample consisting of 61 tea factories is extracted based on the density of the high grown tea factories belongs to the four categories of sub districts namely; Nuwara Eliya, Western, Udu Pussellawa and Uva. 
Auction price is taken as the basic figure for representing the price of the made tea. Required data are obtained from the secondary data sources available in Sri Lanka Tea Board. Research design is developed according to the nature of the data set. Data set of this research belongs to the one of special type of pooled data (combination of time series and cross sectional data) called "Panel/ Longitudinal, or Micro-panel data" which is used in most of survey researches (Gujarati, 2003). In this data set, factories in sample represent the cross sectional or individual and data were collected for each month in the period of January 2009 to December 2011 for each of them in the sample. And data set is balanced panel hence each cross-sectional unit has the same number of time series observations (Gujarati, 2003).

\section{Data Analysis}

Both descriptive analysis and regression analysis was conducted to realize the objective.

Descriptive analysis was done for the sample statistics and econometric analysis was done for panel data estimation.

\section{Econometric Analysis}

The statistical technique of regression analysis is the main tool used to obtain the estimates. OLS method is used to run the regression. Among various models for analyzing the panel data, Fixed Effect panel data regression model is selected by doing pre-tests (Hausman test) for the econometric analysis by considering prime requirements and applicability of the model according to the data set. The following equation is developed for determination of factors affecting for NSA.

$$
Y_{i t}=\beta_{0}+\beta_{1} X_{1 i t}+\beta_{2} X_{2 i t}+\cdots+\beta_{k} X_{k i t}+u_{i t}
$$

$\mathbf{Y}_{\mathbf{i t}}=$ the value of the dependent variable for cross-section unit at time $\mathrm{t}$

- $\quad$ cross sections (tea factories) $\mathrm{i}=1, \ldots, \mathrm{ki}$

- time series ( January $2009-$ December 2011) $t=1, \ldots, k t$

$\mathbf{X}_{\mathbf{k i t}}=$ the value of the $\mathrm{k}^{\text {th }}$ explanatory variable for cross section $\mathrm{i}$ at time $\mathrm{t}$

- There are $\mathrm{k}$ explanatory variables indexed by $\mathrm{k}=1, \ldots, \mathrm{k}$

$\boldsymbol{\beta}=$ Coefficients of explanatory variables, where $\mathrm{k}=1 \ldots \mathrm{k}$

$\boldsymbol{\beta}_{0}=$ Coefficient of constant 
$\boldsymbol{u}_{i t}=$ Error term for $\mathrm{i}^{\text {th }}$ cross section and time series

Selected nine variables are used for the analysis and description of the nine variables used for the analysis is showed in table 1.

Table 1: Description of Variables for Econometric Model of Tea Factories

\begin{tabular}{|l|l|l|}
\hline Notation & Variable & Remarks \\
\hline NSA & Net Sale Average & Sri Lankan Rupees \\
\hline MG & Main grade percentage & \\
\hline CT & Certification holding & 0 to 100\% \\
\hline BL & Bought leaf & If yes =1 , Otherwise $=0$ \\
\hline OWL & Own leaf & kilograms \\
\hline OL & Other leaf & kilograms \\
\hline BLS & Best leaf standard & kilograms \\
\hline BBLS & Below best leaf standard & kilograms \\
\hline PLS & Number of broker & \\
\hline
\end{tabular}

\section{Econometric Model}

Linear Fixed Effect Panel Data model is selected according to the results of Hausman test to run the regression for the analysis. 
The equation for regression of the Panel data FE model:

$$
\begin{aligned}
N S A=\beta_{0}+ & \beta_{1} M G+\beta_{2} C T+\beta_{3} B L+\beta_{4} O W L+\beta_{5} O L+\beta_{6} B L S+\beta_{7} B B L S+\beta_{8} P L S \\
& +\beta_{9} B K+u_{i}
\end{aligned}
$$

where, $\beta_{1}$ to $\beta_{9=}$ coefficients of the explanatory variables and, $\boldsymbol{u}_{\boldsymbol{i}}=$ error term

\section{Housman Test}

Hausman test for the unobserved error component is run and expected if the unobserved effects are exogenous, the FE and RE are asymptotically equivalent (McManus, 2011).

Hypothesis for the Hausman test:

$$
\begin{aligned}
& \mathrm{H} 1: \widehat{\beta}_{\mathrm{FE}} \neq \widehat{\beta}_{\mathrm{RE}} \\
& \mathrm{H} 0: \widehat{\beta}_{\mathrm{FE}}=\widehat{\beta}_{\mathrm{RE}}
\end{aligned}
$$

$\widehat{\beta}_{\mathrm{FE}}$ and $\widehat{\beta}_{\mathrm{RE}}=$ coefficient vectors for the time-varying explanatory variables, excluding the time variables.

Decision rule:

Prob>chi2 (gives in STATA results) $<0.05$ (i.e. significant) null hypothesis is rejected, concluding that RE is inconsistent and the FE model is preferred. If the null hypothesis cannot be rejected, random effects are preferred because it is a more efficient estimator.

\section{Results and Discussion}

\section{Tea Production in High Elevation}

Black tea production within past ten years has been leading by low grown and over the years there were not much significant fluctuations in tea production shares in all elevations (see fig 2).Even though the production is not showing a difference with the time (fig 2), the price figures have been given a substantial variation with the time (fig 1). The reason is the quality of the tea. They are always getting high prices in auction even in small quantities. 


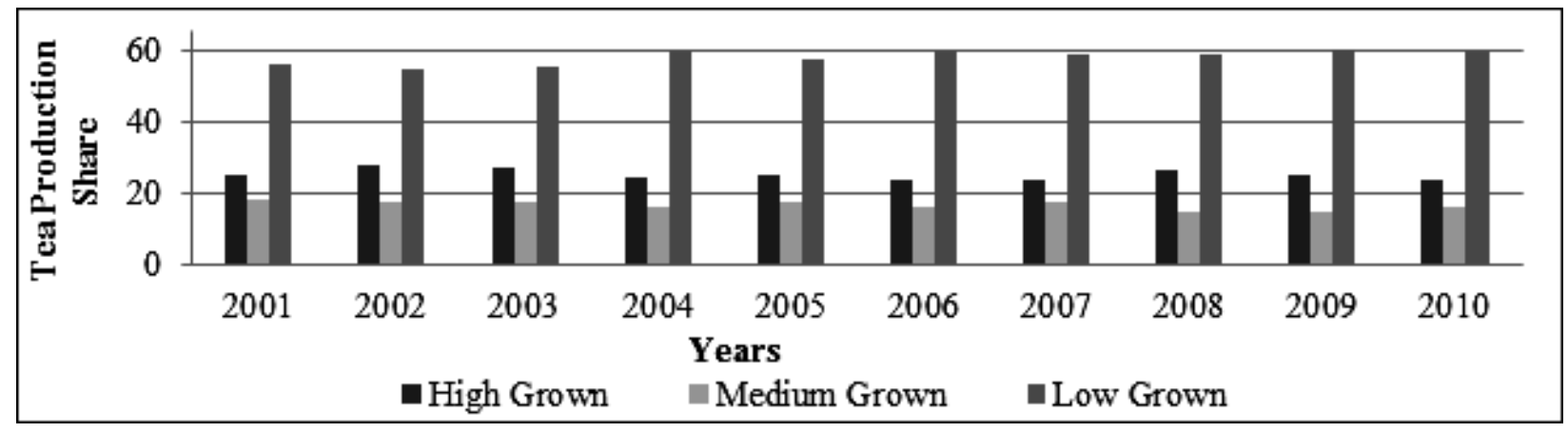

Fig 2: Tea Production Share within Elevations

Tea Research Institute (TRI) has recommended tea with a few main grades as quality teas and increasing the quantity of main grades increases the NSA of the factory. It is proven by the results in fig 3 that peaks and troughs are showing similar pattern both in main grades and NSA. It is due to high prices gained by main grades in public auction as the main grades are always carrying quality teas.

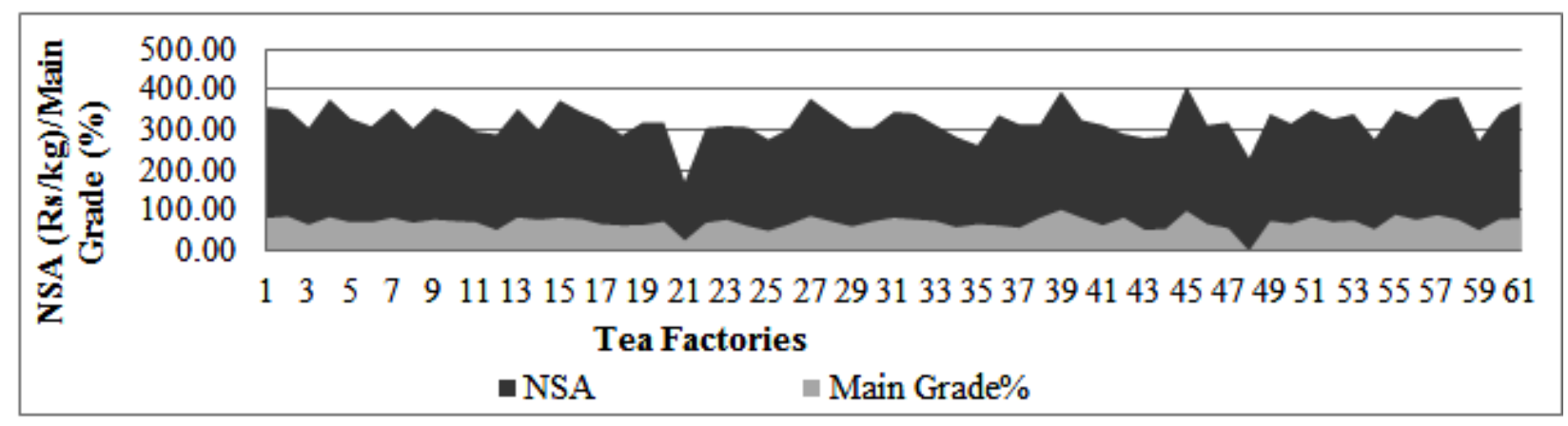

Fig 3: Distribution of NSA and Main Grade \%

Main grades as well as off grades gain high prices in flavor seasons (special agro climatic conditions), due to high demand especially for high elevation teas, because they are mainly considered for their flavor (Mohammed and Dahanayaka, 2008). This situation can be considered as demand factors for made tea and it is due to the relationship of main grade percentage and NSA. While the relationship between main grades and NSA has been maintained, at times off grades receive high prices only due to high demand at the auction, because there are buyers who demand off grades mainly for blending purposes

When considering behavior of percentages of main grades and off grades in the overall elevation (see fig 4), the gap between them is decreasing with time. It is the possible reason for gradual decline of prices and thereby decline of EA in high elevation. 


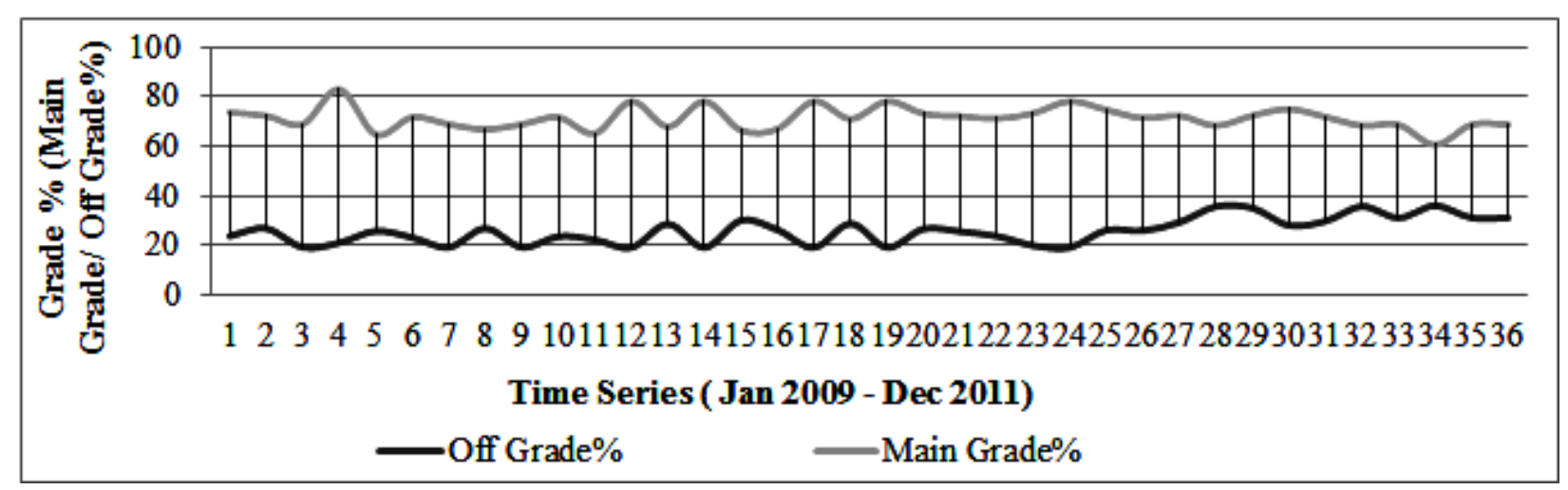

Fig 4: Main Grade and Off Grade Percentages maintained in Three Year

\section{Green Leaf Supply}

Factories receive green leaves from their own estate, other estates that belong to the same management and as bought leaf from small holders. Among three of supply methods, highest percentage $(47 \%)$ goes to own leaf; leaf requirement fulfilled by their own estates. Second highest percentage (40\%) goes to bought leaf supply method and remaining (13\%) is fulfilled by bought leaf suppliers.

Bought leaf factories in high elevation is in very low number when comparing with that of low elevation. Large estates, belong to plantation companies have covered entire leaf requirement almost by themselves (own leaf and other leaf) except few of bought leaf factories that are showing high amount of bought leaf consumption (see fig 5).

Unexpected disease, variation in climate and less fertility of soil are the leading factors for decreasing of leaf standard in own leaf.

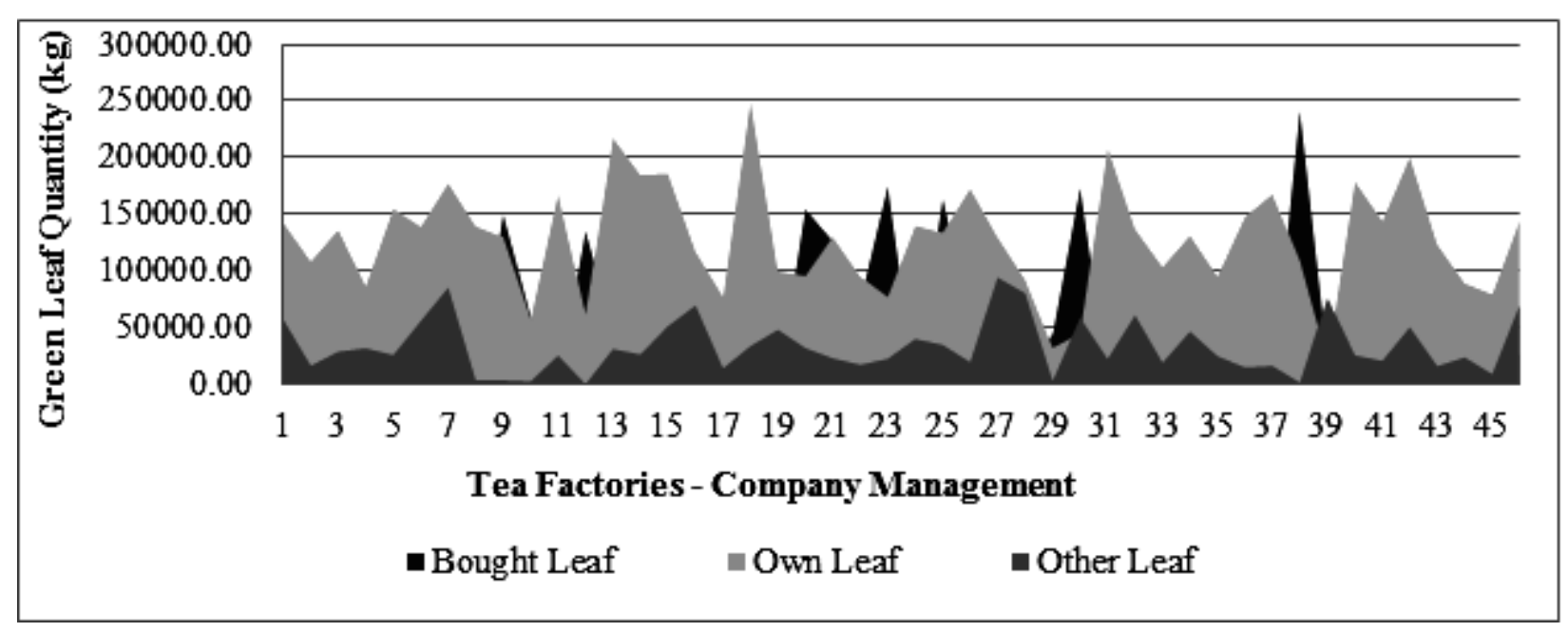

Fig 5: Leaf Supply in Tea Factories under the Company Management 
In this circumstances bought leaf become good solution for maintaining the quality. Moreover, there is an upcoming trend in bought leaf compared to the own estate leaves in high elevation (see fig 6)

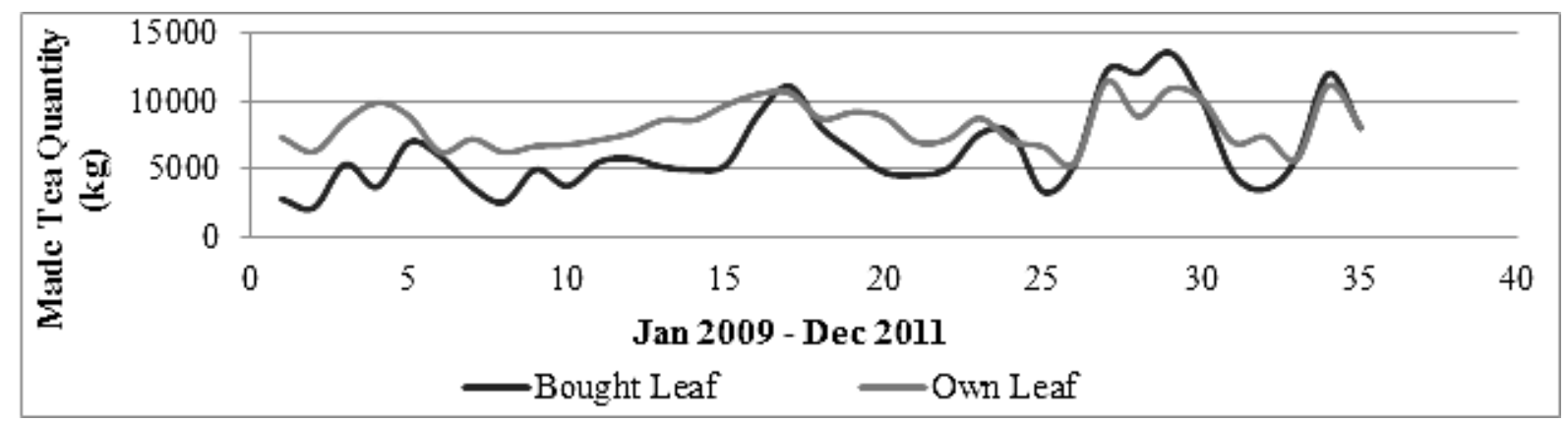

Fig 6: Behavior of Made Tea Produced by Own Leaf and Bought Leaf within Three Years

\section{Green Leaf Standard}

Leaf standard is being critical for making high price for made tea. When considering the recent situation (see fig 7), there had been a tendency of using poor leaf standard leaves for the production during past three years. That could be a reason for price decline in tea factories and gradual declining of EA in high elevation.

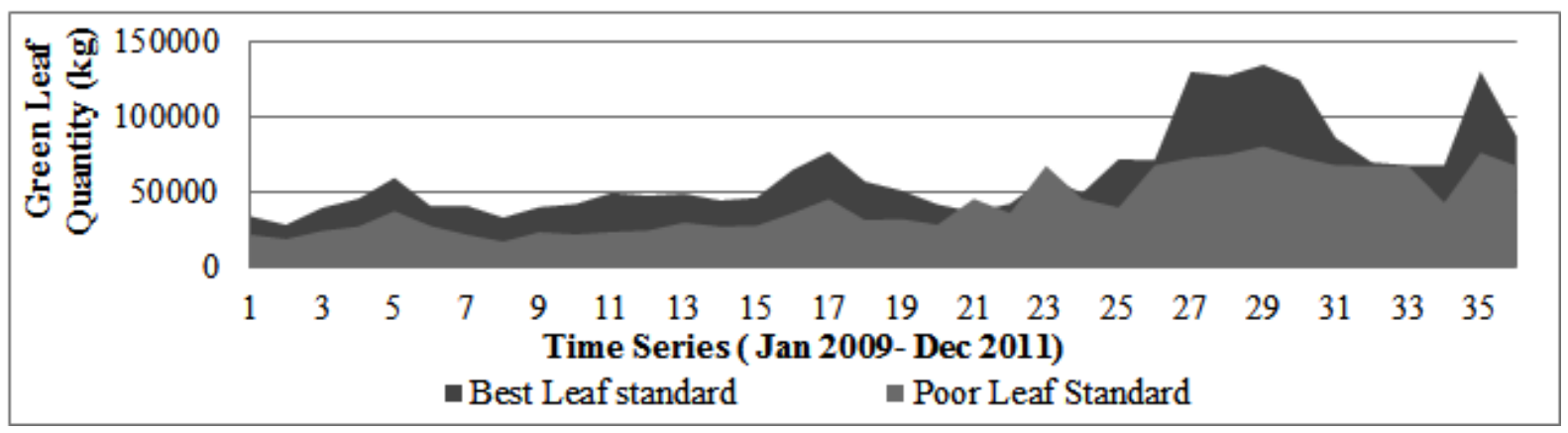

Fig 7: Fluctuations in Green Leaf Quantity of Best and Poor Leaf Standards over Three Years

\section{Certification Holding Tea Factories}

According to the mean values of certifications and non-certification tea factories; 80 percent of tea factories are having International Certification/s that supports to increase the producer's recognition in the tea market. Certification has been included in the catalogs just below the selling mark and it can influence on tea selling prices. And it is indeed an added advantage in selling process because international buyers are highly concerned on the food safety and its 
quality. HACCP and ISO 22000 are standards for food quality and safety. And in very recently Fair Trade; empower the labour giving enough facilities/ fair worker environment, Ethical Tea Partnership (ETP); improving the lives of tea workers and their environment and Rain Forest Alliance; generating positive economic, ecological, and social benefits to the clients who are interested to environment protection came to the tea industry have been introduced to the industry.

\section{Broker Influence}

Some factories mostly use direct sale as disposal method while using public auction too. High elevation factories more tend towards direct sales than those in other two regions. According to the fig 8 , tea factories very often use one broker for their selling process. High grown brokers do not require exerting more effort to sell their teas as high grown teas have the unique character of flavor and they receive higher price in auction without competition. And high elevation produce less number of grades than low elevation, thus implying that buyers are more concerned on liquor quality than appearance of the leaves compared to teas in low elevation. Therefore, high number of intermediaries is not very essential in selling teas in high elevation.

Beyond the condition in high elevation, brokers can be considered as responsibility carriers in selling process and working for high price at the auction. Increasing the number of persons who is holding that responsibility would increase the effectiveness of the selling process. Increasing the number of brokers is a strategy that is used to cover the market environment without using only one broker. Each broker has different connections with different buyers and different skills in marketing. The mix of these different people would increase the bargaining power of the producer and finally the producer would be provided efficient and effective service.

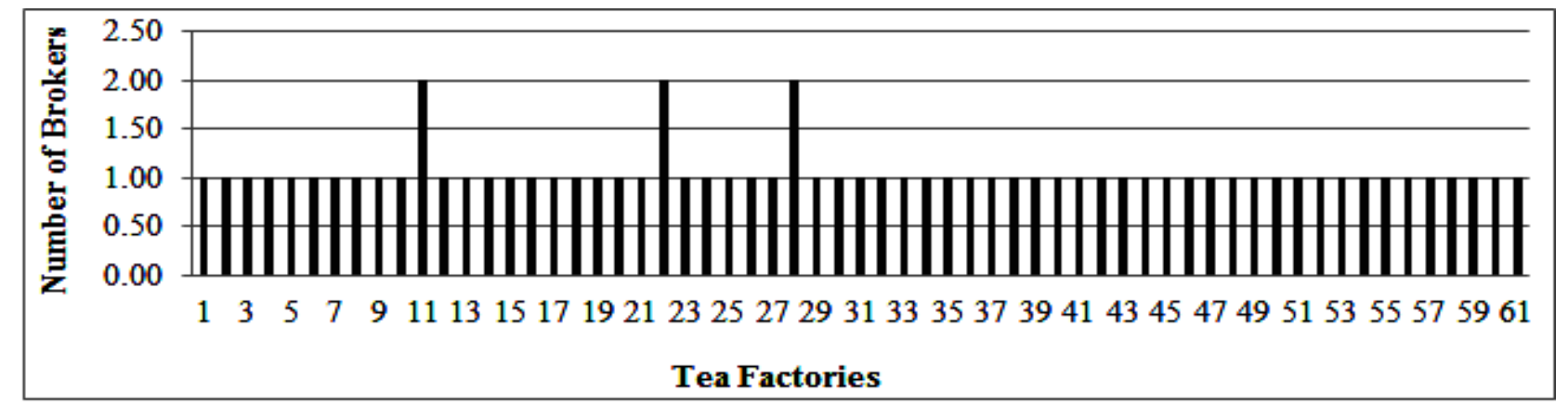

Fig 8: Number of Broker within Tea Factories 


\section{Condition in Flavor Regions}

Western, Nuwara Eliya, Udu Pussellawa and Uva are deserved by unique character in made tea; the flavor which is being considered when setting price at the auction. They are having different agro climatic conditions. Price variation could be affected in different proportions by those determinants. Therefore, main grade percentage, own leaf quantity (the source of the raw material used to produce made tea) and quantity of green leaves in best leaf standard (the quality of raw material) are considered in region wise analysis.

Main grade percentage with NSA of a factory was analyzed for Nuwara Eliya sub district. According to the fig 9, slightly positive relationship between main grade percentage and NSA was identified. But main grade percentage was concentrated from 60 to 100 and different prices have resulted in three years period. That could be due to the quality difference in made tea produced in those periods as tea price would vary by the quality not by the main grade percentage.

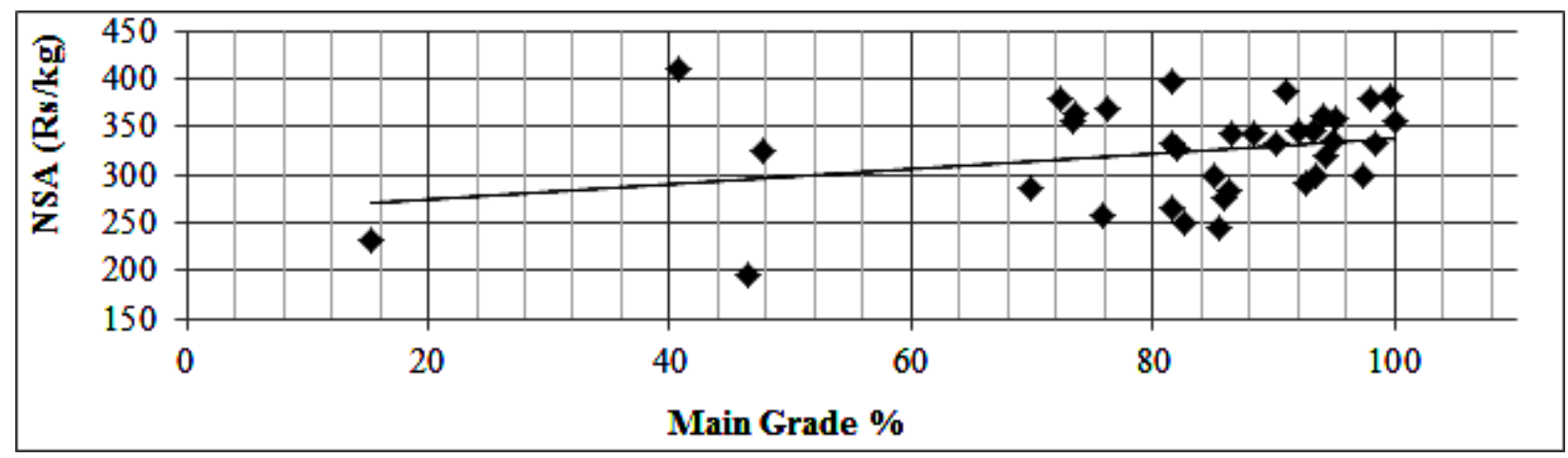

Fig 9: Relationship of Main Grade Percentage with NSA in Nuwara Eliya

Own leaf quantity with NSA (see fig 10) shows weak relationship compared to the main grade percentage with NSA (see fig 9). Even though they have used same own leaf quantity, different NSA is resulted due to quality difference in raw material and changing favorable climatic conditions throughout the time period (Nuwara Eliya is getting their flavor season in January to February). 


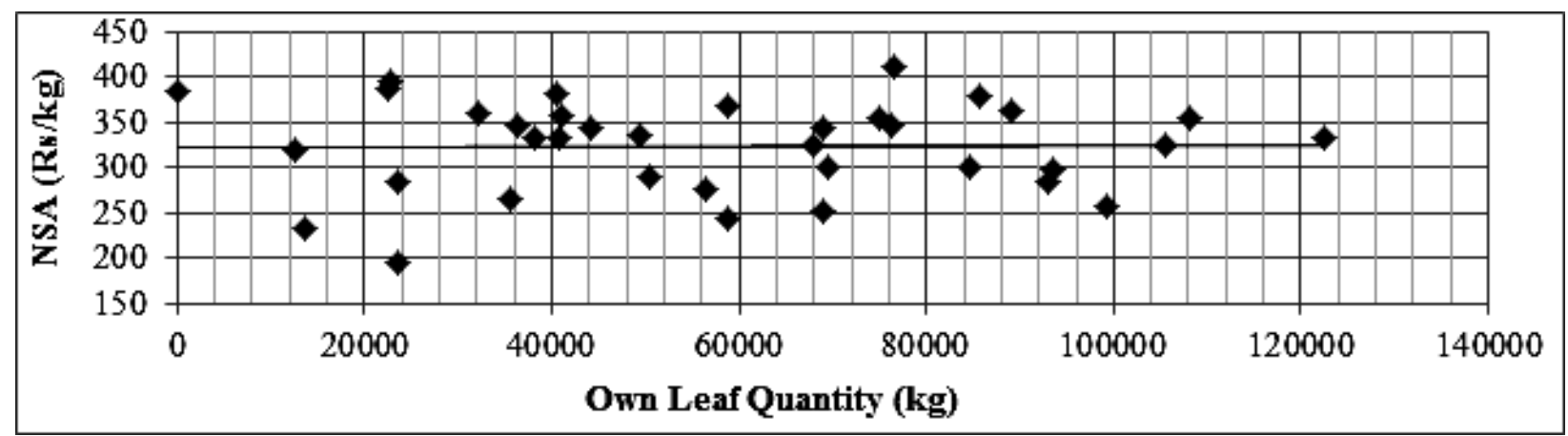

Fig 10: Relationship of Own Leaf Quantity with NSA in Nuwara Eliya

According to the fig 11, best leaf standard green leaf is given positive relationship for the NSA. But same leaf standard has given different NSA values throughout the time period. Flavor developed in made tea varies with the time due to changing favorable climate during that time. It could be the leading factor for price variation for same leaf standard.

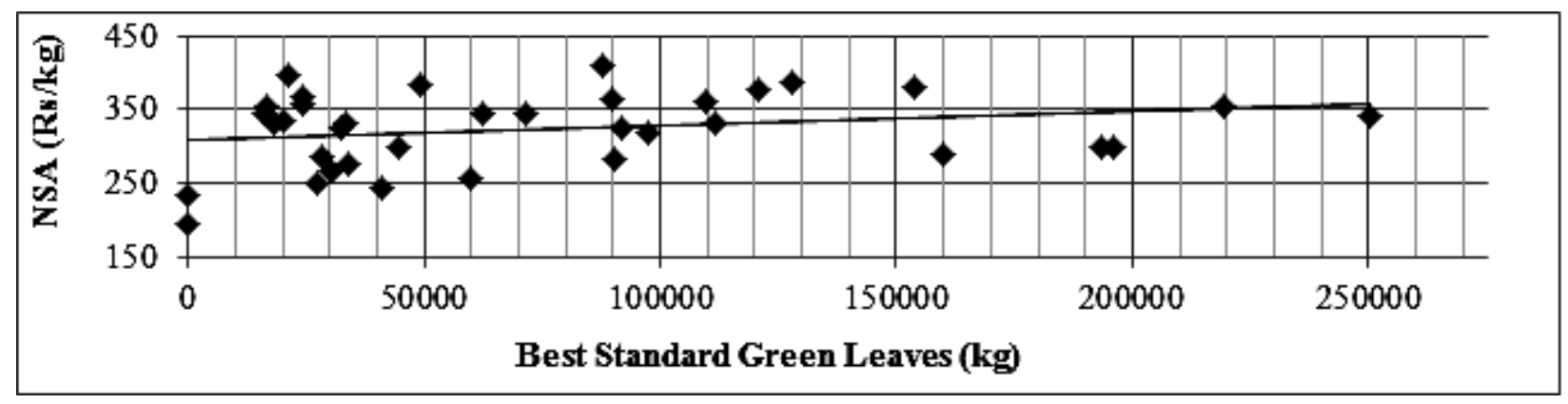

Fig 11: Relationship of Best Leaf Quantity with NSA in Nuwara Eliya

\section{Western Sub Region}

As in Nuwara Eliya, western sub district shows positive relationship (see fig 12) for main grade percentage with NSA. Main grade percentage is concentrated to 65 to 75 and some of main grade percentages which are having same values are given different NSA in different times. The flavor based price determination could be the reason for this variation. 


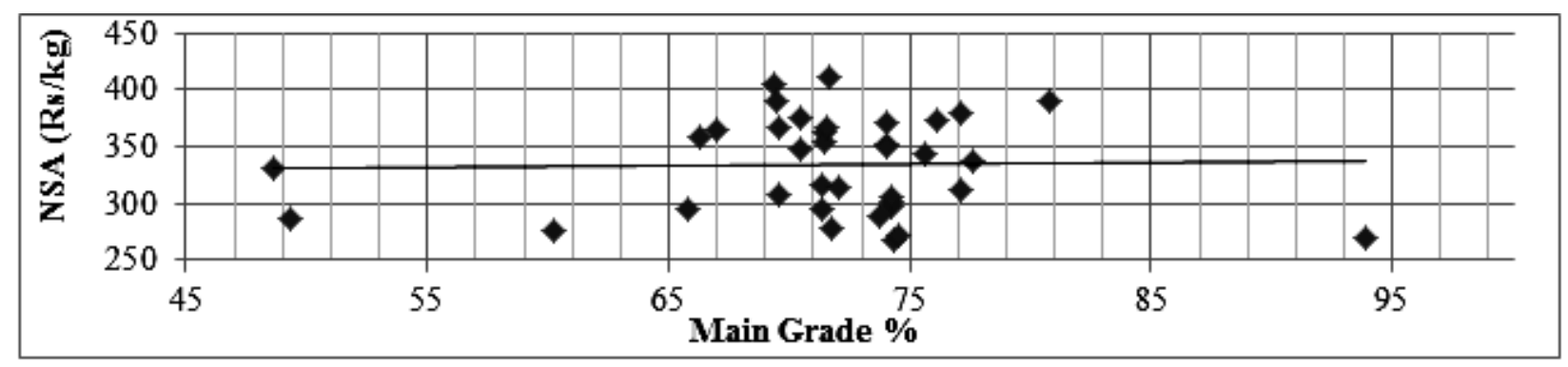

Fig 12: Relationship of Main Grade Percentage with NSA in Western

When considering the source of the green leaves for produce made tea, the own leaf has given positive relationship with NSA than in Nuwara Eliya. But same conditions appeared in variations of NSA for equal own leaf values (see fig 13).

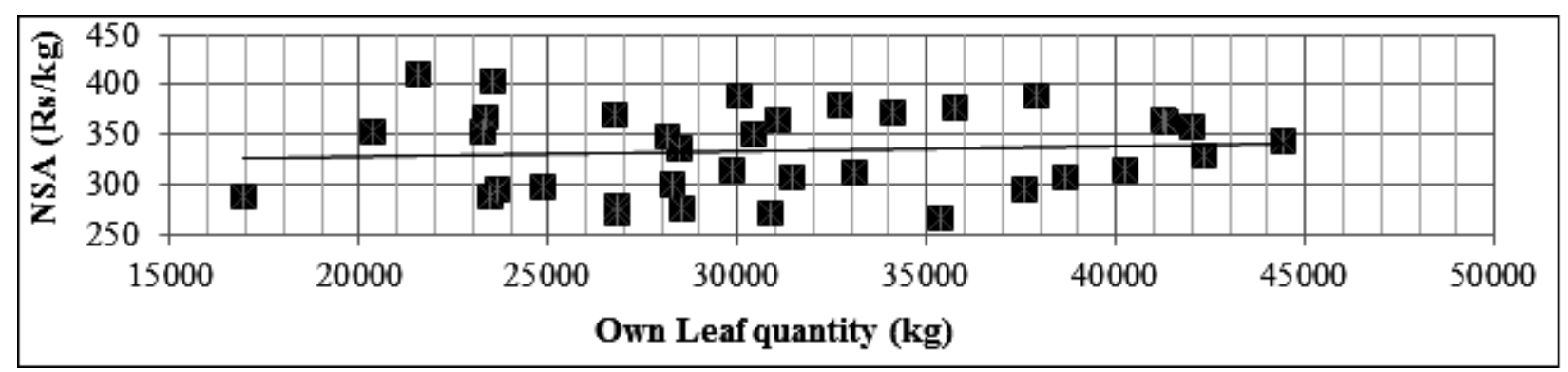

Fig 13: Relationship of Own Leaf Quantity with NSA in Western

Best leaf standard maintaining in western region has a given positive relationship with NSA and showed price variation for equal quantity due to influence of some external factors that are highly affecting for price determination (see fig 14). High demand for flavor teas could be the reason for this variation.

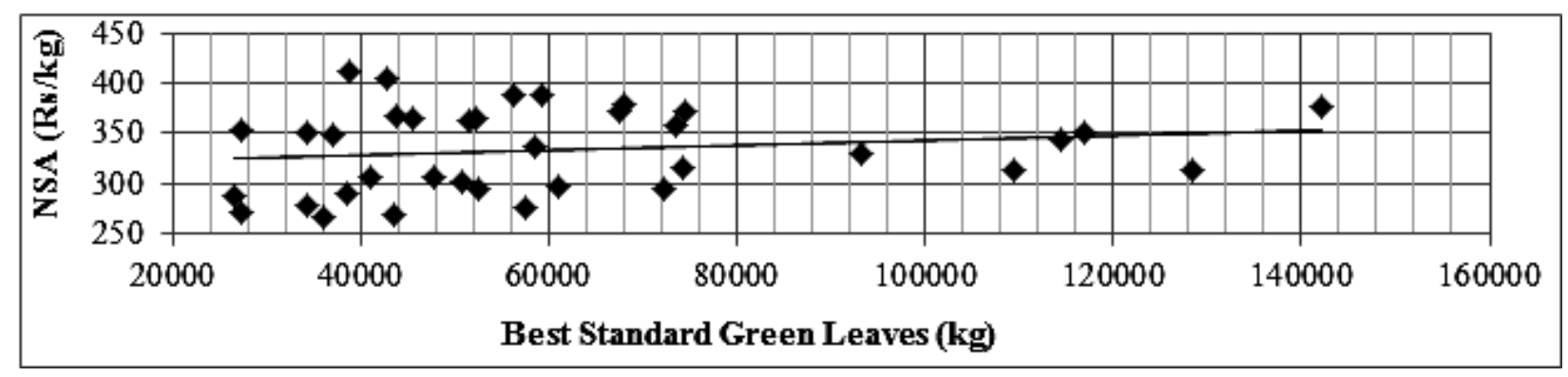

Fig 14: Relationship of Best Leaf Quantity with NSA in Western 


\section{Udu Pussellawa}

According to the analysis the results are same as in above two sub districts, Udu Pussellawa showed same results for main grade percentage as a NSA determinant (see fig 15).

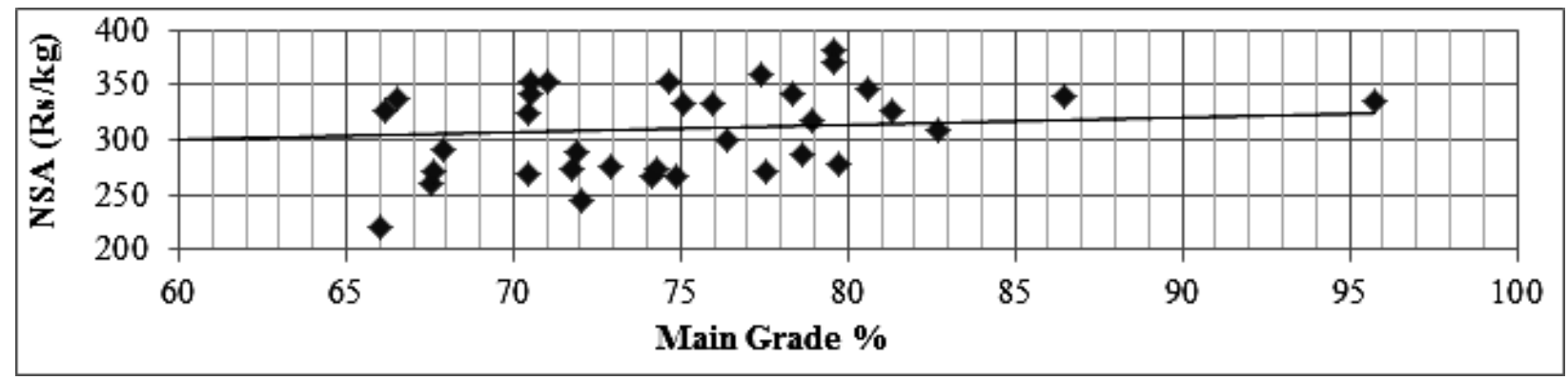

Fig 15: Relationship of Main Grade Percentage with NSA in Udu Pussellawa

The source of raw material (own leaf) and the quality of raw material (leaf standard) with NSA is given opposite results in UduPussellawa (see fig 16 and 17).

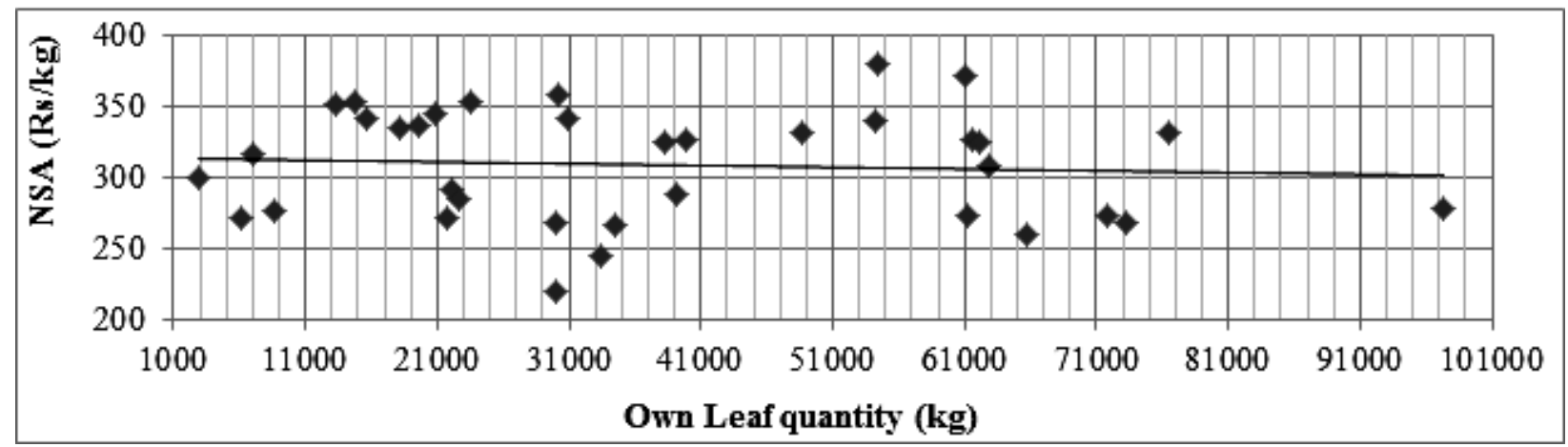

Fig 16: Relationship of Own Leaf Quantity with NSA in Udu Pussellawa

Results revealed that there is factor in own leaf affecting the price which has not shown in Nuwara Eliya and Western regions. That is, when comparing the results of main grade percentage, the low quality in own leaf can be the reason. In the situation of best leaf standard, negative results denote that some external demand factors are influencing the price determination because low prices have obtained for high percentage of main grades produced with high quality raw materials. 


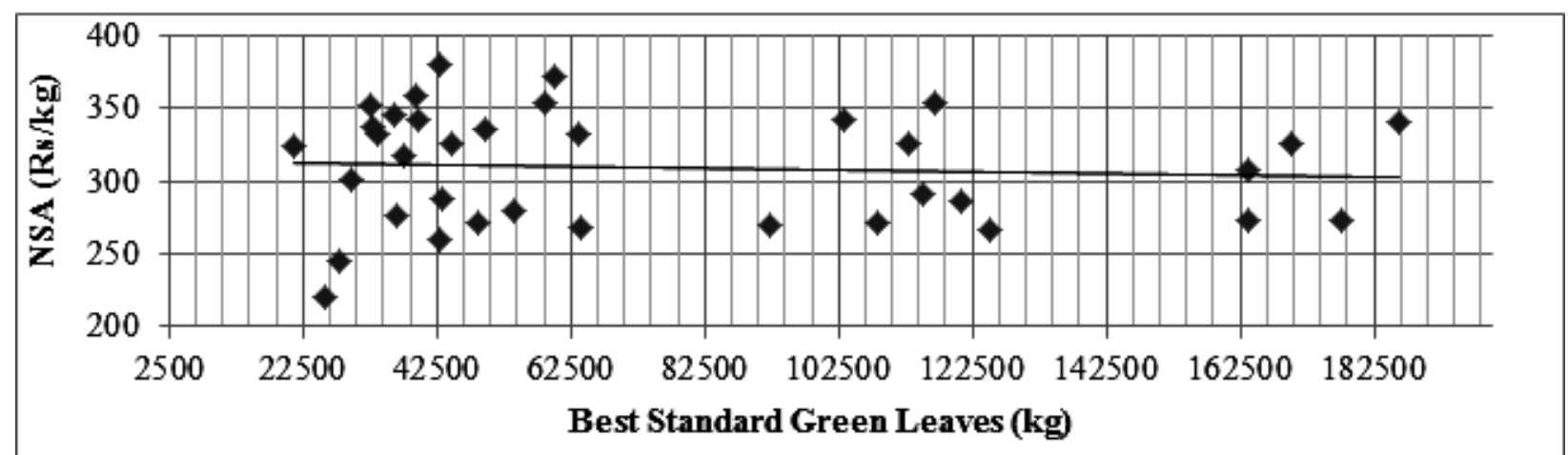

Fig 17: Relationship of Best Leaf Quantity with NSA in Udu Pussellawa

\section{Uva}

Unlike in other regions, Uva has showed negative relationship for the main grade percentage and NSA (see fig 18). And it was concentrated to 60 to 75 percentages and as in other regions, Uva show low price variation for main grades.

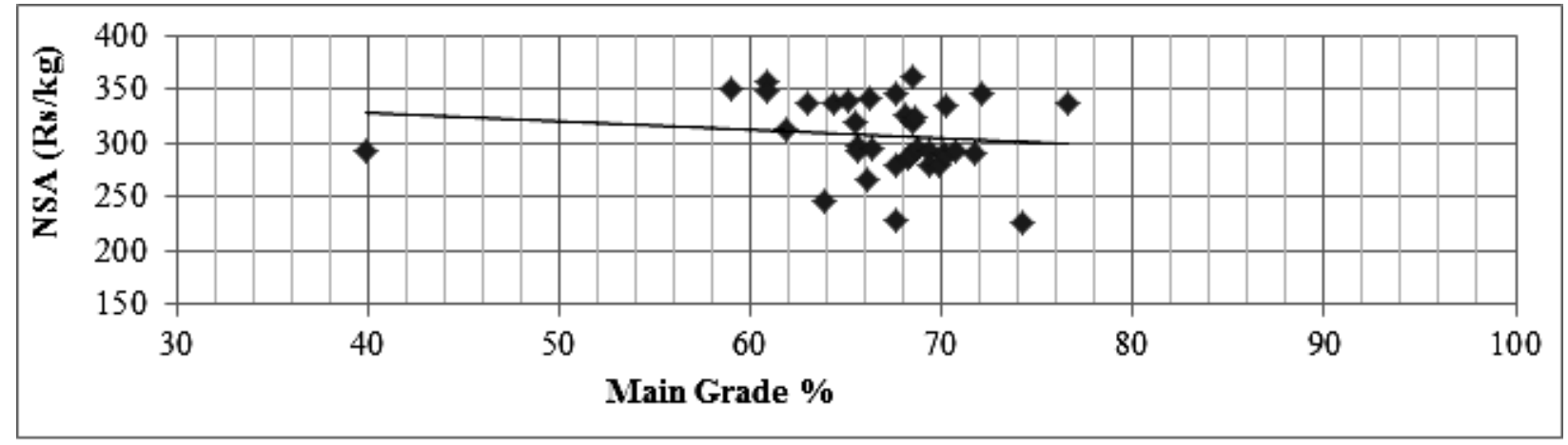

Fig 18: Relationship of Main Grade Percentage with NSA in Uva

According to the fig.19 and 20, price variation in Uva is not substantial. Both graphs show different NSA values with same leaf quantities and vice versa. Therefore besides the own leaf quantity on making the price variations, there could be some other reasons which affects the price. 


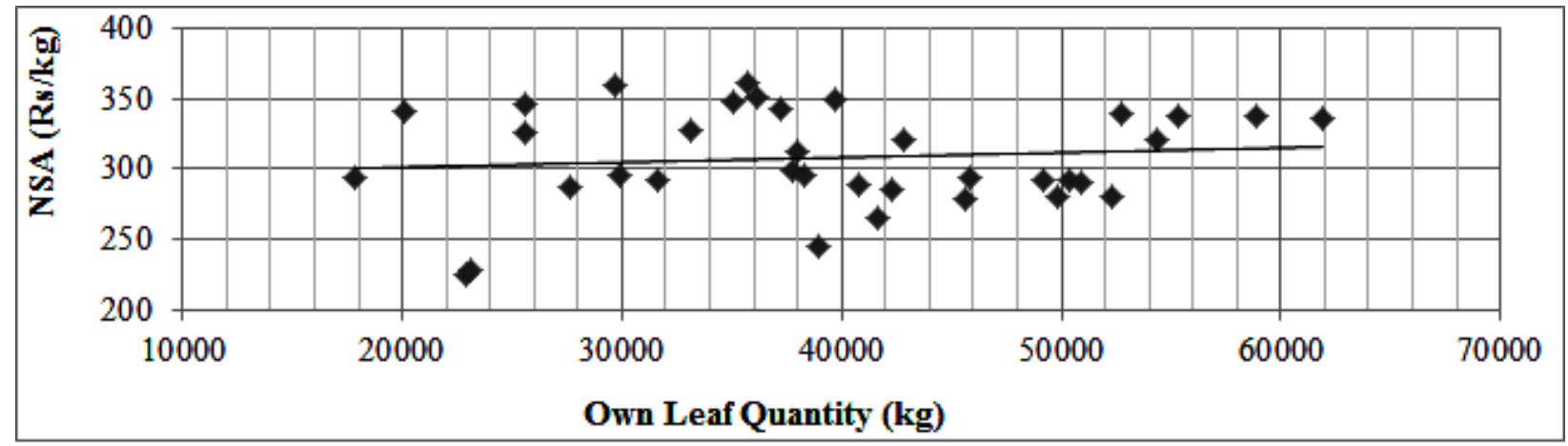

Fig 19: Relationship of Own Leaf Quantity with NSA in Uva

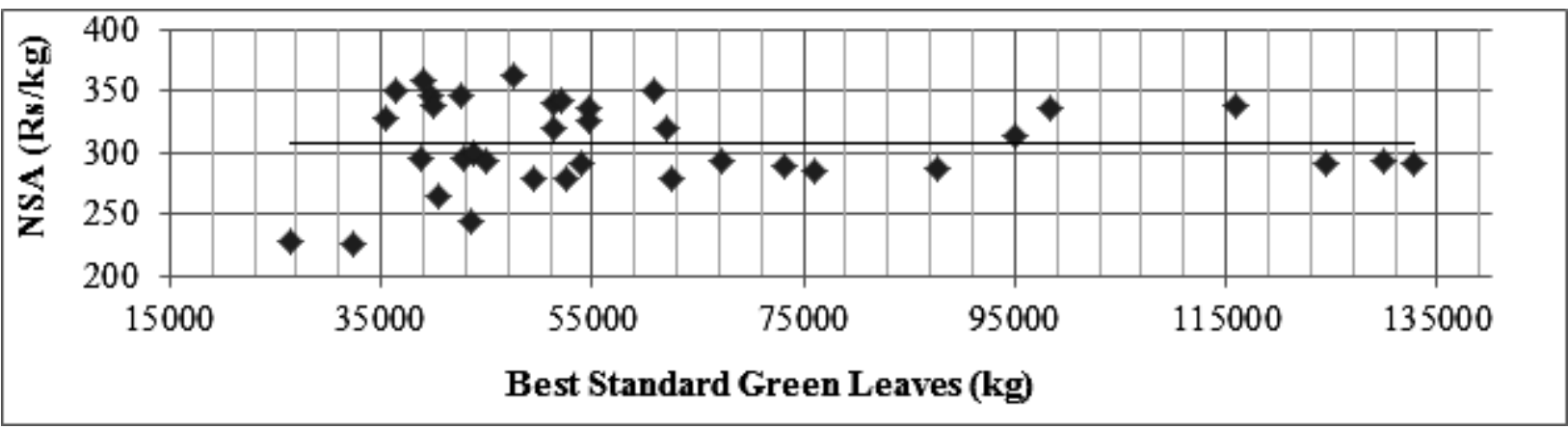

Fig 20: Relationship of Best Leaf Quantity with NSA in Uva

The low quality in own leaf and other demand factors that affect in price formulation (even though tea is produced by high quality leaves) can be the reasons for these results.

Determinants of NSA of Orthodox Black Tea Factories in High Elevation (Panel Data Estimation)

According to the results of Housman test, linear Fixed Effect (FE) model is selected for the econometric analysis. Description of the results of econometric analysis is depicted in table 2 .

Results revealed that the NSA of tea factories in high elevation was significantly determined by main grade percentage that factory produced in the particular month, certifications that particular tea factory has obtained, quantity of green leaves from their own estates, green leaf quantity from best leaf standard, number of brokers they have, dealing with as positive relationships at $1 \%$ significant level. 
Table 2: Results of Panel Data Regression Analysis

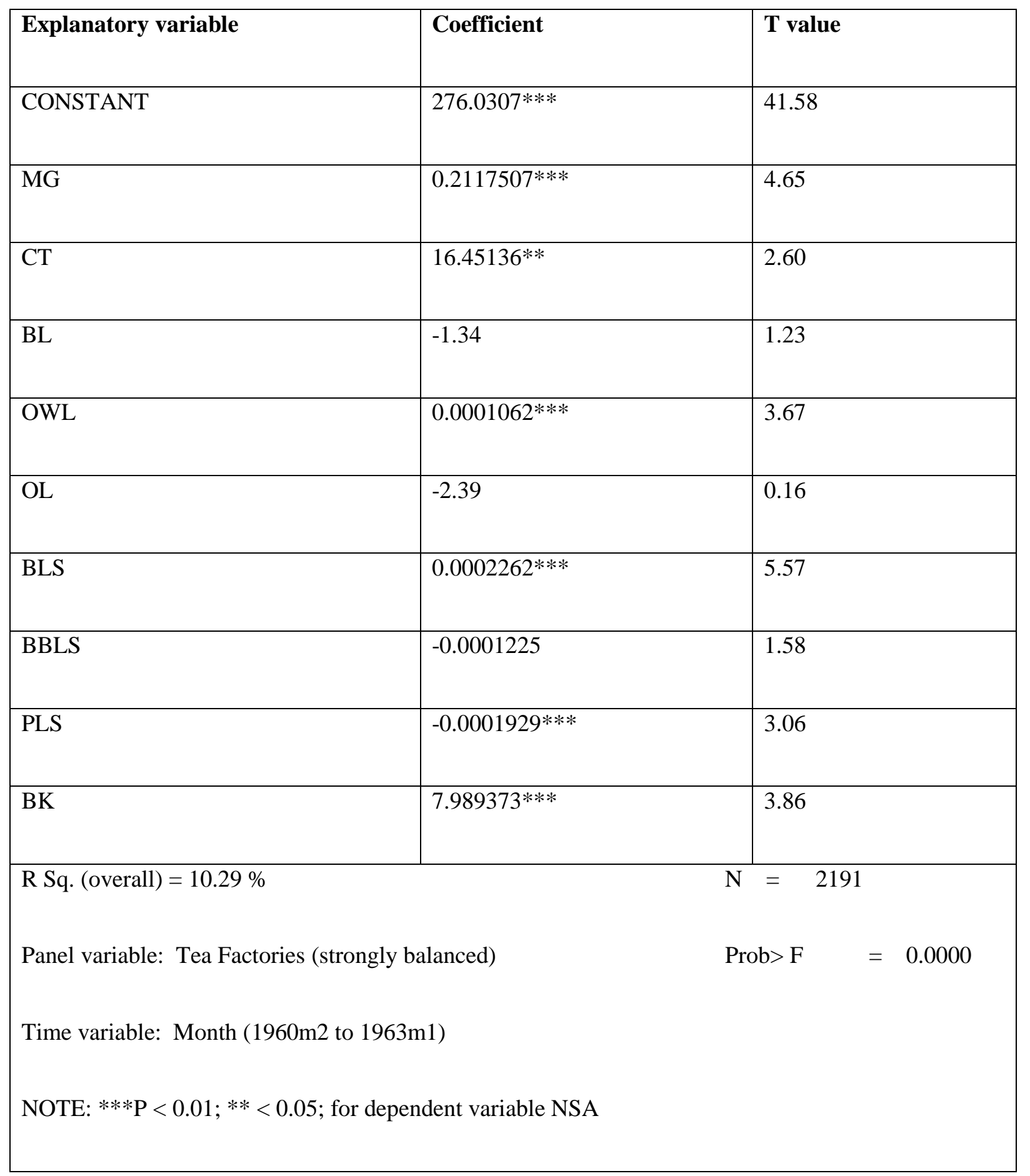

Green leaf quantity of poor leaf standard has negative relationship with NSA of tea factory at 5\% significant level. According to the analysis, there is no significant relationship between green leaf quantity from bought leaf and other leaf (from other estates) and green leaf quantity of below best leaf standard at any significant level.

The quantity of green leaves having poor leaf standard has given negative significance for this study in ratio of 1: 0.0001929 . It is approximately twice than the best leaf standard effect to the 
NSA. Quantity of below best leaf standard green leaves shows non-significant negative relationship with NSA. It may be due to some unknown intermediate impact.

Bought leaf quantity that consumed for tea making process was not significant in this analysis and it has given negative relationship though. A few bought leaf factories are located in high elevation, whereas majority of tea factories fulfill their leaf requirement by their own estate leaves. Inadequate awareness in post-harvest losses, less adaption in plastic baskets for harvesting and transporting of green leaves and less facilities provided for leaf suppliers by large estates (no transport facilities, less incentives for good leaves) could be the reasons for insignificance for bought leaf in price determination. Consuming high amount of bought leaf could be the reason for price declining in high elevation.

\section{Conclusion and Recommendations}

According to the results obtained through panel data estimation, the determinants of NSA are representing overall quality of the made tea.

When considering the significant variables of the analysis, main grade percentage that factory produced for the particular month, certifications that respective tea factory has obtained, quantity of green leaves from their own estates, green leaf quantity with best leaf standard, number of brokers they have been dealing in selling process and they highly influence the factory NSA. It is recommended that above factors can be prioritized in any factory modernization in order to increase the factory income. Main grade percentage represents the quality tea grades recommended by TRI for tea particle attributes. Its expectation was to maintain the competition on quality tea in auction and thereby increase the factory NSA. This research attempts to encourage factory management to make quality teas rather than following demand on low quality teas purposely made for blending. If factory could focus on increasing main grades percentage they can sustain in the market. In regional analysis, the results revealed that they have been sustained by the high income coming in flavor seasons. In off seasons they are running low income and not concerned about the determinants of NSA.

Further, it is revealed that green leaf quantity of poor leaf standard has negative relationship with NSA of tea factory at high significant level but less than the above main factors. There is no significant relationship for green leaf quantity from bought leaf and other leaf (from other estates) and green leaf quantity of below best leaf standard at any significant level. Even in the below best leaf standard having moderate quality in raw material, it has given negative effect for final product quality. Maintaining raw material quality which means the leaf standard in best 
category is essential for better quality in final product. Therefore, it is recommended to start maintaining the raw material quality at the harvesting stage. Own estates have given significant positive effect on NSA (bought leaf and other estate leaf having negative and no significance on NSA), Good Agricultural Practices (GAP) can be easily applied to their own estates. To maintain the leaf quality in their own leaves they have to implement integrated programs for plucking policies, awareness programs for workers, facilitate enough plastic baskets for plucking and transporting in order to minimize the post- harvest loses. After all there could be low quality made tea due to wrong manufacturing practices. Therefore, both cultivation practices and manufacturing should be integrated to make the high quality final product. Every decision that management has taken for the cultivation and manufacturing should be aimed at the final product.

Number of brokers in the selling process has given high positive significance for factory NSA. It can be concluded that increasing of number of brokers influences on high NSA. As a suggestion allocating one broker for special grades can be applied for the selling process. The relationship between broker and producer should be increased further in order to receive an effective service. This relationship facilitates both parties to exchange the information on market requirements with producer capabilities. Worldwide importers are mainly managed to obtain their requirements through the Colombo Auction via brokers. Direct sales to the international markets have been maintained at a minimum level. In that scenario, tea brokers are the only one that participates actively to the selling process to contact buyers, make agreements and negotiations about fair tea prices. Their efficiency has become very important thus eight numbers of brokering firms are in Sri Lanka and this few number handle millions of kilograms of tea per week. If factory could increase number of brokers they can obtain services from various origins of brokers and their different strategies will ultimately give the high prices to the producer.

In the meantime, most consumer countries are willing to purchase quality assured products under the WTO agreements on sanitary. Consequently, the corporate sector (RPC) have to invest heavily on factory modernization, integration of tea based products, market promotion/sales promotion ,etc. thus corporate sector is having highest proportion of extent in high elevation. Since tea is an export commodity, the impacts from the world market directly influence the domestic production and marketing processes of this commodity. And the product; tea should be compatible with not only the consumption pattern but also with their concepts regarding the product. International regulations relating to food safety, ethical and social issues that are concerned by the consumer can be used as a tool for attracting people from world market. Because of the competitive nature in world market this is the high time to turn into new market 
strategies rather than depending on traditional methods. Adapting HACCP, ISO 22000, Ethical Tea Partnership (ETP), Rain Forest Alliance, Fair Trade, etc, certifications could enhance the reputation of the producer and thereby increase the NSA. And the major challenges are finding financial, human and social capital in order to invest for modernization of the product and marketing processes. In this scenario, authorities of Sri Lankan tea sector can implement a national program for adapting international certifications and regular auditing program for measure the success.

According to the descriptive analysis on flavor regions, it is concluded that each region has behaved differently compared to the main analysis. Especially Udu Pussellawa and Uva region have deviated from the elevation pattern. Therefore, it is essential to conduct further and deep analysis for determinants of NSA for four of flavor regions. Because of their own characteristics of flavor, they have got range of prices. It indeed depends on the time of the year and climate conditions. Therefore further study should be done for the regions separately and considering long time period. It is recommended that instead of using an EA considering entire elevation for comparing the factory performance there should be a separate unit price for each region. It could be an effective measurement for the further development programmes and studies.

And it is finally concluded that self - analysis for every factory could be a good solution for better identification of their strengths and weaknesses in cultivation and manufacturing. It could be an individual participation for increase the EA in high elevation. Relevant authorities can guide the factory people and facilitate through investments. It could be suggested to maximize the factory NSA, it is essential to capitalize every opportunity to reach the sustainable of the industry. For an instance market the reputation of the Ceylon tea brand image by responsible authorities could be suggested. In order to experience the benefits, market intelligence for identifying the international market needs and as well as particularly maintaining the demand driven by the quality of the product should be included in program content.

\section{References}

Anon, (2005).Forest Gold; The Story of South Indian Tea”, UPASI Coonoor Publishers

Bassanini, A. and Scarpetta, S., (2001). The Driving Forces of Economic Growth: Panel Data Central Bank of Sri Lanka, Statistical Bulletin (2011). Central Bank of Sri Lanka

Evidence for the Oecd Countries. OECD Economic Studies 2001/II. No. 33, pp 9-56 
Farid, N., and Rahman, S. M., (2002).Market Structure and Price Determination of Food Grains in Bangladesh.Early Warning and Food Information System Project, Ministry of Food, Bangladesh

Fernando, M., (2008).Twentieth Century Tea Research Sri Lanka; Diversity: The Hallmark of Ceylon Tea. pp. $393-403$

Gujarati. D. N., (2003). Basic Econometrics.Fourth Edition.McGraw HiII/lrwin.

McManus, P. A. (2011). Introduction to Regression Models for Panel Data Analysis Indiana University Workshop in Methods

Mohammed and Dahanayake, (2008).Twentieth Century Tea Research Sri Lanka; Studies and Opinions of Up Country Tea Manufacturing. pp. $361-364$

Sri Lanka Tea Board, Annual Report, (2009). Sri Lanka Tea Board

Tea Traders Association, Sri Lanka, Annual Report (2011) Tea Traders Association, Sri Lanka 